\title{
EPAC1 Inhibition Protects the Heart from Doxorubicin-Induced
}

\section{Toxicity}

Marianne Mazevet ${ }^{1 \#}, \mathrm{PhD}$, Maxance Ribeiro ${ }^{1 \#}, \mathrm{PhD}$, Anissa Belhadef ${ }^{1}$, MSc, Delphine

Dayde $^{1}, \mathrm{PhD}$, Anna Llach${ }^{1}, \mathrm{PhD}$, Marion Laudette ${ }^{2}$ PhD, Tiphaine Belleville ${ }^{3}, \mathrm{PhD}$, Philippe Mateo ${ }^{1}, \mathrm{MSc}$, Mélanie Gressette ${ }^{1}, \mathrm{MSc}$, Florence Lefebvre ${ }^{1}, \mathrm{Ju} \mathrm{Chen}^{4}, \mathrm{PhD}$, Christilla Bachelot-Loza ${ }^{3}, \mathrm{PhD}$, Catherine Rucker-Martin ${ }^{6}, \mathrm{PhD}$, Frank Lezoualc'h ${ }^{2}, \mathrm{PhD}$, Bertrand Crozatier $^{1}, \mathrm{MD}$, Jean-Pierre Benitah ${ }^{1}, \mathrm{PhD}$, Marie-Catherine Vozenin ${ }^{5}, \mathrm{PhD}$, Rodolphe Fischmeister ${ }^{1}$, PhD, Ana-Maria Gomez ${ }^{1}$, PhD, Christophe Lemaire ${ }^{1,7 *}$, PhD, and Eric Morel ${ }^{1 *}$ PhD.

\#These authors contributed equally to this work

*These authors contributed equally to the senior authorship of this manuscript

${ }^{1}$ Université Paris-Saclay, Inserm, UMR-S 1180, 92296, Châtenay-Malabry, France

2Institut des Maladies Métaboliques et Cardiovasculaires - I2MC - UMR 1048 INSERM, Université de Toulouse, 31432, Toulouse, France

${ }^{3}$ Innovations Thérapeutiques en Hémostase - UMR-S 1140, INSERM, Faculté de Pharmacie, Université Paris Descartes, Sorbonne Paris Cité, Paris, France

${ }^{4}$ Basic Cardiac Research UCSD School of Medicine La Jolla, California, US

${ }^{5}$ Laboratoire de Radio-Oncologie, CHUV, Lausanne, Switzerland

${ }^{\circ}$ Faculté de Médecine, Université Paris-Saclay, Le Kremlin Bicêtre, France

Inserm UMR_S 999, Hôpital Marie Lannelongue, Le Plessis Robinson, France

${ }^{7}$ Université Paris-Saclay, UVSQ, Inserm, UMR-S 1180, 92296, Châtenay-Malabry, France

\section{Corresponding author:}

Eric Morel

UMR-S 1180 - Laboratory of Signaling and Cardiovascular Pathophysiology

Faculté de Pharmacie, Université Paris-Saclay

5, rue Jean-Baptiste Clément, 92296, Châtenay-Malabry

Phone : (+33) (0)1-46-83-53-20 ; Mail : eric.morel@,universite-paris-saclay.fr

\section{Word Count: 7,961}

Subject codes: Cardio-Oncology, Cardiotoxicity, Pathophysiology 


\section{Summary}

Rationale: The widely used chemotherapeutic agent Doxorubicin (Dox) induces cardiotoxicity leading to dilated cardiomyopathy and heart failure. This cardiotoxicity has been related to ROS generation, DNA intercalation, bioenergetic distress and cell death. However, alternative mechanisms are emerging, focusing on signaling pathways.

Objective: We investigated the role of Exchange Protein directly Activated by cAMP (EPAC), key factor in cAMP signaling, in Dox-induced cardiotoxicity.

Methods and Results: Dox was administrated in vivo $(10 \pm 2 \mathrm{mg} / \mathrm{kg}$, i.v.; with analysis at 2, 6 and 15 weeks post injection) in W'T and EPAC1 KO C57BL6 mice. Cardiac function was analyzed by echocardiography and intracellular $\mathrm{Ca}^{2+}$ homeostasis by confocal microscopy in isolated ventricular cardiomyocytes. 15 weeks post-injections, Dox-treated WT mice, developed a dilated cardiomyopathy with decreased ejection fraction, increased telediastolic volume and impaired $\mathrm{Ca}^{2+}$ homeostasis, which were totally prevented in the EPAC1 KO mice.

The underlying mechanisms were investigated in neonatal and adult rat cardiac myocytes under Dox treatment $(1-10 \mu \mathrm{M})$. Flow cytometry, Western blot, BRET sensor assay, and RT-qPCR analysis showed that Dox induced DNA damage and cardiomyocyte cell death with apoptotic features rather than necrosis, including $\mathrm{Ca}^{2+}-\mathrm{CaMKK} \beta$-dependent opening of the Mitochondrial Permeability Transition Pore, dissipation of the Mitochondrial membrane potential $(\Delta \Psi \mathrm{m})$, caspase activation, cell size reduction, and DNA fragmentation. Dox also led to an increase in both cAMP concentration and EPAC1 protein level and activity. The pharmacological inhibition of EPAC1 (CE3F4) but not EPAC2 alleviated the whole Dox-induced pattern of alterations including DNA damage, $\Delta \Psi \mathrm{m}$, apoptosis, mitochondrial biogenesis, dynamic, and fission/fusion balance, and respiratory chain activity, suggesting a crucial role of EPAC1 in these processes. Importantly, 
while preserving cardiomyocyte integrity, EPAC1 inhibition potentiated Dox-induced cell death in several human cancer cell lines.

Conclusion: Thus, EPAC1 inhibition could be a valuable therapeutic strategy to limit Doxinduced cardiomyopathy without interfering with its antitumoral activity.

Key words: Doxorubicin, Cardiotoxicity, Prevention, Cardio-oncology, EPAC1

Nonstandard Abbreviations and Acronyms

8-CPT

8-(4-chloro-phenylthio)-2'-O-methyladenosine-

3'-5'cyclic monophosphate

$\beta-A R$

$\beta$-adrenergic receptor

ARVM

Adult Rat Ventricular Myocyte

BAA

Biotin-conjugated ADTM analog

$\mathrm{Ca} 2+$

Calcium

CaMKK $\beta$

$\mathrm{Ca} 2+/$ calmodulin-dependent protein kinase

kinase $\beta$

DCM

Dilated cardiomyopathy

Dox

Doxorubicin

EF

Ejection fraction

EPAC

Exchange Protein directly Activated by

cAMP

FDA

Fluorescein di-acetate

HF

Heart failure

KO

Knock-Out

LVEDV

Left ventricle end-diastolic volume

MCU

Mitochondrial Ca2+ Uniporter 
bioRxiv preprint doi: https://doi.org/10.1101/2021.06.16.448655; this version posted June 17, 2021. The copyright holder for this preprint (which was not certified by peer review) is the author/funder. All rights reserved. No reuse allowed without permission.

MPTP

NRVM

PI

Ruth Red

TopII $\beta$

WT
Mitochondrial Permeability Transition Pore

Neonatal Rat Ventricular Myocytes

Propidium Iodide

Ruthenium Red

Topoisomerase II $\beta$

Wild Type 


\section{Introduction}

Doxorubicin (Dox), which belongs to the anthracyclines family, is one of the most frequently used anticancer agent for the treatment of adult and childhood leukemia/lymphoma and various solid tumors, including sarcomas, breast, ovarian, and lung cancers. ${ }^{1}$ However, despite its clinical efficacy as an anticancer agent, Dox therapeutic use is restricted due to its side-effects, including cardiotoxicity. ${ }^{2}$ The main risk factors for Dox-induced cardiomyopathy are cumulative dose (ranging from $5 \%$ at $400 \mathrm{mg} / \mathrm{m}^{2}$ to $48 \%$ at $700 \mathrm{mg} / \mathrm{m}^{2}$ ) and age (children before the age of five and elderly patients after 60 years old) $\cdot^{3-5}$ Dox cardiotoxicity can be acute with cardiac disorders such as arrhythmias only few hours after the first injection, or chronic with complex and cardiac remodeling cardiomyopathies (dilated cardiomyopathy (DCM), heart failure (HF)) years after treatment. ${ }^{6}$

Dox is supposed to induce irreversible type I cardiotoxicity characterized by structural damages of cardiac tissue, including myofibrils loss, cytosol vacuolization, and cardiomyocyte death, which lead to decreased contractile force and myocardial dysfunction. ${ }^{7}$ Mechanistically, Dox, a DNA Topoisomerase II ( $\alpha$ and $\beta$ ) inhibitor, induces DNA double strand break by direct DNA interaction, ${ }^{8}$ oxidative stress, ${ }^{9,}{ }^{10}$ and decreased ATP production. ${ }^{11}$ In response to DNA damage and ROS production, p53 cascade, an upstream signaling pathway of Dox-mediated toxicity, leads to the activation of the mitochondrial pathway of apoptosis. ${ }^{12}$ In addition, the necrosis induced by massive ROS production and ATP depletion was also proposed to be a primary mechanism of Dox-induced cardiomyopathy. ${ }^{13,}{ }^{14}$ Furthermore, Dox is also known to induce various mitochondrial alterations, including mitochondrial biogenesis, dynamic, and energy homeostasis defects. ${ }^{15-18}$ In addition to the dogma, more recent innovative hypotheses, centered on signaling pathways, have been proposed to better understand the Dox-induced cardiotoxicity mechanisms. The cardiac-specific deletion of Topoisomerase II $\beta$ (TopII $\beta$ ) has been shown to inhibit Doxinduced DNA damage and heart failure, ${ }^{19}$ leading to the conclusion that TopII $\beta$ is an important 
driver of Dox-induced cardiotoxicity located upstream to the core cell death pathways (apoptosis, necrosis, energetic distress). More recently, it has been proposed that blockade of the molecular target PI3K $\gamma$ can simultaneously prevent anthracyclines cardiotoxicity and reduce tumor growth, ${ }^{20}$ providing a potential dual advantage in cancer therapy.

Currently, new effective and noncontroversial clinical cardioprotective therapies are still lacking and numerous strategies are under active investigation. A variety of molecules (statins, coenzyme Q10, beta-blockers, angiotensin II receptor blockers, erythropoietin, amifostine, and dexrazoxane) have been tested as cardioprotective adjuvants in preclinical studies. However, only the iron chelator dexrazoxane is approved by the Food and Drug Administration and the European Society of Cardiology as a cardioprotective agent for anthracyclines. ${ }^{6,21,22}$ Nevertheless, its use remains controversial due to potential incidence of second malignancies and reduced cancer treatment efficacy. ${ }^{23}$ Therefore, there is an urgent need to develop new therapeutic strategies that can provide long-term cardioprotection against Dox-induced cardiotoxicity without compromising its antitumoral efficacy.

The exchange factor EPAC (Exchange Protein directly Activated by cAMP) contributes to the hypertrophic effect of $\beta$-adrenergic receptor $(\beta-A R)$ chronic activation in a cAMP-dependent but protein kinase A-independent manner in in vitro/vivo models and in heart biopsies from HF patients. $^{24,25}$ At the molecular level, EPAC is a guanine-nucleotide-exchange factor for the small G-protein Rap. ${ }^{26,27}$ The EPAC1 isoform is mainly expressed in human hearts compared to EPAC2 isoform and is increased in $\mathrm{HF}^{24}$ In cardiomyocytes, EPAC stimulation regulates calcium $\left(\mathrm{Ca}^{2+}\right)$ signaling by activating CaMKII. ${ }^{28-30}$ In pathological conditions, EPAC promotes cardiac remodeling through pro-hypertrophic signaling pathways, which involve nuclear $\mathrm{Ca}^{2+} / \mathrm{H}-$ Ras/CaMKII/MEF2 and cytosolic $\mathrm{Ca}^{2+} / \mathrm{Rac} / \mathrm{H}-\mathrm{Ras} /$ Calcineurin/NFAT. ${ }^{25}$, 26, 28-30 Although the role of EPAC in cardiomyocyte apoptosis remains controversial, ${ }^{31-33}$ its role in adaptive autophagy was recently confirmed in cardiac hypertrophic pathology. ${ }^{34}$ 
Several of these molecular actors, which are part of EPAC1 signalosome, have been independently shown to be involved in Dox-induced cardiotoxicity signaling ( $\mathrm{Ca}^{2+}$ homeostasis, RhoA, Rac). ${ }^{35-37}$ However, the role of EPAC itself in that context is not known and thus could be one of the upstream bandmaster of Dox-induced cardiotoxicity.

Recent findings indicate also a cardioprotective role of EPAC inhibition in response to ischemia/reperfusion injury. ${ }^{38}$ In addition, EPAC was shown to contribute to cardiac hypertrophy and amyloidosis, but not fibrosis, induced by radiotherapy. ${ }^{39} \mathrm{EPAC}$ has also been shown to play a role in various cancers (breast, thyroid, pancreatic, melanoma, etc. ${ }^{40,41}$ and tumoral processes (EMT transition, metastasis, intratumoral innervation, cell migration and proliferation, cytoskeletal remodeling, etc.). ${ }^{42-44}$ All these observations suggest that EPAC may represent a potential therapeutic target for cancer treatments. ${ }^{41,45}$

Herein, we determined the role of EPAC in Dox-induced cardiotoxicity. Using the specific EPAC1 inhibitor, CE3F4, we demonstrated for the first time, that EPAC1 but not EPAC2 inhibition protects cardiac cells from DNA damage, mitochondrial alterations, and $\mathrm{Ca}^{2+}$-CaMKK $\beta$ dependent apoptosis elicited by Dox. The cardioprotective role of EPAC1 inhibition was also confirmed in vivo, as the genetic deletion of EPAC1 in mice prevents the long term (15 weeks) Doxinduced DCM. In addition, regulation of $\mathrm{Ca}^{2+}$ homeostasis, mitochondrial biogenesis and function as well as prevention of TopII $\beta$-related DNA damage were identified as part of the mechanisms whereby EPAC1 inhibition reduced Dox cardiotoxicity. Importantly, EPAC1 inhibition not only protected cardiomyocytes from Dox-induced cell death but also potentiated Dox-induced toxicity in various cancer cell lines, suggesting EPAC1 as a new and valuable therapeutic target. 


\section{Methods}

\section{Animal study}

All animal experiments were conducted in accordance with the ethical principles of the French and European Union Council Directives for the care of laboratory animals 86/609/EEC, under the MESRI 18927 authorization.

Model

12 weeks old C57BL6 (Wild Type littermate (WT) or EPAC1 Knock-Out ${ }^{46}(\mathrm{KO})$ ) male mice received i.v. (tail vein) $\mathrm{NaCl}(0.09 \%)$ or Dox $(4 \mathrm{mg} / \mathrm{kg}, 3$ times at 3 days intervals, cumulative dose of $10 \pm 2 \mathrm{mg} / \mathrm{kg}$, in order to mimic human therapeutic regimen). ${ }^{20}$ This dose allows cardiac physiological parameters alterations with the induction of moderated dilated cardiomyopathy without inducing death. ${ }^{47}$ Only male have been considered in order to avoid the female hormonal cardioprotection. Cardiac function was measured at 2, 6 and 15 weeks after the last injection. Ventricular myocytes were isolated at the same analysed times for $\mathrm{Ca}^{2+}$ handling measurements and Western blot analysis as previously detailed. ${ }^{48}$

\section{Cell culture}

\section{Dissociation of Neonatal (NRVM) and Adult (ARVM) Rat Ventricular Myocytes}

NRVM were isolated from 1-3 days old Sprague-Dawley rats (40 pups in average per dissociation) (Janvier, Le Genest-Saint-Isle, France). Ventricules were digested with collagenase A (Roche, Meylan, France) and pancreatin (Sigma Aldrich, St Quentin Fallavier, France), separated by a Percoll gradient and were plated (DMEM/medium 199 (4:1) (ThermoFischer Scientific, Les Ullis, France)). Langendorff method was used to isolate ARVM as previously described. ${ }^{49}$ 


\section{Treatments}

Doxorubicin $(2 \mathrm{mg} / \mathrm{mL})$ and dexrazoxane were obtained respectively from ACCORD (central pharmacy of Institut Gustave Roussy, Villejuif, France) and Sigma (St Quentin Fallavier, France). The in vitro Dox concentration exposure of isolated cardiomyocytes was of 1-10 $\mu \mathrm{M}$ in concordance with literature recommendation ${ }^{11}$ and extended to match tumor cell lines exposure requirements.

8-(4-chloro-phenylthio)-2'-O-methyladenosine-3'-5'cyclic monophosphate (8-CPT), ESI-09, and ESI-05 were purchased from Biolog Life Science Institute (Bremen, Germany). ZVAD-fmk was purchased from Bachem (Bubendorf, Switzerland). EPAC1 specific inhibitor (R)-CE3F4 was kindly provided by Dr Yves Ambroise (CEA, Gif-sur-Yvette, France). ${ }^{50}$

\section{Statistical analysis}

Results are expressed as mean \pm SEM. Differences between 2 groups have been analyzed by nonparametric Mann-Whitney test. The comparison between more than 2 groups was analyzed by Kruskal Wallis test followed by post hoc test with Bonferroni correction. Differences were considered significant at ${ }^{*} \mathrm{p}<0.05,{ }^{* *} \mathrm{p}<0.01$, and ${ }^{* * *} \mathrm{p}<0.001$ vs $\mathrm{Ctl}$ and \# vs Dox alone. 


\section{Results}

\section{Doxorubicin induced DNA damage and mitochondrial caspase-dependent apoptosis in cardiomyocytes}

In order to characterize the Dox induced cell death profile in our model, we performed time response curves of Dox exposure $(1 \mu \mathrm{M})$ ranging from $12 \mathrm{~h}$ to $48 \mathrm{~h}$ by flow cytometry analysis. Representative monoparametric histograms of FDA fluorescence and TMRM fluorescence, and representative biparametric cytograms for cell size selection, in the presence or absence of EPAC1 inhibitor, are presented in Figures S1A, S1B \& S1C, respectively. Figure 1A shows a timedependent increase of FDA negative cells, indicative of cell death and characterized by a cell size reduction (Figure 1B), a loss of $\Delta \Psi \mathrm{m}$ indicative of mitochondrial membrane permeabilization (Figure 1C) and a decrease in DNA content (Figure 1E). By contrast, Dox did not increase the percentage of PI positive cells, indicating that cardiomyocytes' plasma membranes were not damaged, thus excluding necrosis in our model (Figure 1D). These results indicate that Dox induced an apoptotic process in cardiac cells through the mitochondrial pathway. In addition, the level of the active (cleaved) forms of the mitochondrial-dependent initiator caspase 9 and the executive caspase 3 were increased after Dox treatment (Figure 1F \& 1G). In the same line, the general caspase inhibitor ZVAD-fmk $(50 \mu \mathrm{M})$ prevented Dox-induced increase in FDA negative cells and small cells (Figure 1H \& 1I), suggesting a caspase-dependent mechanism. DNA damages induced by Dox $(1 \mu \mathrm{M})$ were assessed by measuring the level of phospho- $\mathrm{H}_{2} \mathrm{AX}\left(\mathrm{H}_{2} \mathrm{AX}-\mathrm{pS}_{139}\right)$, a sensitive marker of DNA double strand breaks in cultured NRVM at 16 hours, in order to observe the underlying mechanisms prior to the Dox-induced cell death. Figure 1J shows that Dox treatment increased the level of $\mathrm{H}_{2} \mathrm{AX}-\mathrm{pS}_{139}$ indicating DNA damage. Altogether, these results demonstrate that in our model Dox induced DNA damage and apoptosis via mitochondrial- and caspase-dependent pathways in cardiomyocytes without necrosis induction. 


\section{Dox triggered cAMP-EPAC1 pathway in cardiac cells}

To determine whether EPAC1 is involved in Dox-induced cardiotoxicity, we first analyzed EPAC1 protein level and activity after Dox treatment in NRVMs. We observed an up-regulation of EPAC1 protein (Figure 2A) by Dox during the acute phase response (3 $\mathrm{h}$ and $6 \mathrm{~h}$ ) which decreased when apoptosis is triggered (24 h). The activity of EPAC1, recorded over time using a Pull-Down assay of Rap1, showed an increase upon Dox treatment to similar levels as those observed with the EPAC activator 8-CPT $(10 \mu \mathrm{M})$ (Figure 2B). This increase in EPAC1 activity upon Dox treatment was confirmed using a CAMYEL BRET-sensor assay

(Figure 2C), along with an increase of intracellular cAMP concentration, known to directly activate EPAC1 (Figure 2D). In addition, EPAC signaling was altered by Dox treatment. Indeed, the prohypertrophic calcineurin/NFAT pathway (Figure 2E \& 2F) as well as NFuB-Luc activity (Figure 2G) were downregulated by Dox, while MEF2-Luc activity was increased (Figure 2H). By contrast, neither Rac1 expression, nor its activity was modified by Dox treatment (Figure S2). These results show for the first time that Dox induced an increase in both EPAC1 expression and activity and altered EPAC1 downstream signaling pathway in cardiomyocytes.

To test the selectivity of these EPAC signaling modulations, the new EPAC1 pharmacological inhibitor, CE3F4 $(10 \mu \mathrm{M})$ was used. As shown in Figure 3A, CE3F4 decreased $\mathrm{H}_{2} \mathrm{AX}$ phosphorylation promoted by Dox, suggesting less DNA double strand breaks. Similarly, EPAC1 knockdown by shRNA (shEPAC1, Figure 3B top panel) decreased Dox-induced phosphorylation of $\mathrm{H}_{2} \mathrm{AX}$ (Figure 3B lower panel). Moreover, the specific EPAC activator, 8CPT, increased Dox-induced $\mathrm{H}_{2} \mathrm{AX}$ phosphorylation, while the nonselective EPAC1/EPAC2 inhibitor, ESI-09, but not the selective EPAC2 inhibitor, ESI-05, prevented Dox-induced phosphorylation of $\mathrm{H}_{2} \mathrm{AX}$ (Figure S3A). These results suggest that the specific inhibition of EPAC1 isoform prevented the formation of Dox-induced DNA double strand breaks. 
Recently, Topoisomerase II $\beta$ has been suggested to play a central role in anthracyclines' side effects since Dox stabilizes the cleavable complex DNA/TopII $\beta$ which generates DNA double strand break. ${ }^{51}$ Therefore, we examined the relation between EPAC and TopII $\beta$. We first observed that EPAC activation with 8-CPT led to an overexpression of TopII $\beta$, whereas EPAC1 inhibition by ESI-09 or CE3F4 resulted in a decreased of TopII $\beta$ protein expression to the same level as with the dexrazoxane treatment (Figure S3B). We then performed a Band depletion assay to quantify the free TopII $\beta$ protein, not involved in the DNA/TopII $\beta$ complex (Figure S3C). Dox treatment ( 1 and $10 \mu \mathrm{M})$ decreased the quantity of free TopII $\beta$ indicative of the formation of DNA/TopII $\beta$ cleavable complexes, an effect in part prevented by ESI-09, but not ESI-05. Altogether, these results suggest that EPAC1, but not EPAC2, is regulating TopII $\beta$ and involved in Dox-induced DNA damage and that pharmacologic inhibition of EPAC1 may be useful to prevent DNA/TopII $\beta$ cleavable complex formation and the subsequent DNA double strand breaks induced by Dox.

We also investigated whether EPAC1 is involved in Dox-induced apoptosis. The increase in the level of active caspase 9 (Figure 3C) and caspase 3 (Figure 3D) and in the percentages of FDA negative cells (Figure 3E) and small cells (Figure 3F) induced by Dox were significantly reduced in the presence of EPAC1 inhibitor CE3F4. Interestingly, the protection conferred by CE3F4 was comparable to that observed with the clinically approved dexrazoxane (Figure 3E). The micrographs shown in Figure 3G depict the morphology of NRVM in the presence or absence of Dox and CE3F4. While many cardiomyocytes treated by Dox aggregated and rounded up, suggestive of dying cells, most cells exhibited normal shape when the culture was supplemented with CE3F4.

The protective activity of CE3F4 was also tested in freshly isolated ARVM, in order to validate these data in a more differentiated model. As in NRVM, EPAC1 inhibition (CE3F4) protected ARVM from Dox-induced cell death (Figure 3H), while ESI-05 did not (Figure 3I). These data 
demonstrate that pharmacological inhibition of EPAC1, but not EPAC2, attenuated Dox-induced cell death both in NRVM and ARVM, suggesting that there is an EPAC isoform specificity (in favor of EPAC1) in the Dox-associated toxicity in cardiac cells.

\section{EPAC1 inhibition reduced Dox-induced mitochondrial alterations}

As metabolism and mitochondrial disorders are an important pattern of Dox cardiotoxicity downstream of TopII $\beta$ signalling alterations, we next investigated whether EPAC1 inhibition protects NRVM from Dox-induced mitochondrial alterations. As shown in Figure 4A, CE3F4 reduced the Dox-evoked dissipation of $\Delta \Psi \mathrm{m}$. Prolonged opening of the MPTP is one of the mechanisms known to initiate mitochondrial membrane permeabilization leading to $\Delta \Psi \mathrm{m}$ loss. MPTP opening was thus analyzed in NRVM by flow cytometry using calcein-cobalt assay. Dox treatment elicited opening of the MPTP (calcein negative cells), which was decreased by EPAC1 inhibition (Figure 4B). To evaluate the possible involvement of $\mathrm{Ca}^{2+}$ in Dox-induced MPTP opening, mitochondrial depolarization and cell death were measured in Dox treated cells in the presence of the $\mathrm{Ca}^{2+}$ chelator BAPTA-AM $(20 \mu \mathrm{M})$ or Ruthenium Red (Ruth Red), an inhibitor of the mitochondrial $\mathrm{Ca}^{2+}$ uniporter (MCU). Dox-induced MPTP opening (calcein negative cells, Figure 4C), mitochondrial membrane permeabilization (TMRM low cells, Figure 4D), and cell death (FDA negative cells, Figure 4E) were all decreased in presence of BAPTA-AM or Ruth Red, as well as with the inhibition of $\mathrm{Ca}^{2+} /$ calmodulin-dependent protein kinase kinase $\beta$ (CaMKK $\beta$ ) by STO-609 $(25 \mu \mathrm{M})$. These results suggest that the $\mathrm{Ca}^{2+}$-CaMKK $\beta$ axis contributes to Dox-induced MPTP opening and activation of the mitochondrial pathway of apoptosis in cardiomyocytes.

Given that Dox was reported to induce a dysregulation of mitochondrial biogenesis and a collapse of energy in cardiac cells ${ }^{16}$ and that MPTP opening can lead to mitochondrial bioenergetics failure, the effects of EPAC1 inhibition on mitochondrial biogenesis, dynamic and function were analyzed. To this end, the mRNA levels of the main genes involved in mitochondrial biogenesis (Pgc1 $\alpha$, Tfam, Ppar $\alpha$, Cpt1b, and Nrf1 and 2) were quantified by RT-qPCR. Dox treatment severely 
decreased expression of these genes, effects partially and/or completely prevented in the presence of CE3F4 (Figure 4F). Dox treatment also decreased the expression of the mitochondrial fusion genes Opa1 and Mfn1, but did not alter the expression of the fission-related gene Drp1 (Figure $4 G)$, thus leading to a fission/fusion imbalanced toward the fission, which was prevented by CE3F4. We next evaluated the mitochondrial function by measuring the activity of the complex I and IV by cytochrome $\mathrm{C}$ oxidase and ubiquinone oxidoreductase activities measurements in NRVM treated or not with Dox \pm CE3F4. Dox elicited a decrease in complex I and IV activity, which was prevented by EPAC1 inhibition (Figure 4H \& 4I). Altogether, these data indicate that inhibition of EPAC1 by CE3F4 protects NRVM from Dox-induced decrease in mitochondrial biogenesis, dynamic, and function.

\section{Dox induced a dilated cardiomyopathy in C57BL6 mice 15 weeks post-treatment with global alteration of EPAC1 signaling}

Since the above results showed a strong protection of EPAC1 inhibition following ex vivo Dox treatment on various parameters (cell death, mitochondria, and DNA damages) in NRVM and ARVM, we tested a potential cardioprotective effect of EPAC1 inhibition in vivo. Heart samples from our previously published fractionated Dox i.v. mouse model ${ }^{48}$ showed that while the expression of EPAC1 and RhoA were increased 6 weeks after Dox treatment and strongly decreased at 15 weeks, when DCM is detected (Figure 5A \& 5B) no significant modification of Rap1 expression was observed (Figure 5C). In addition, the decreased expression of Rac1 observed at 2 weeks after Dox treatment was followed by a compensation at 6 weeks (Figure 5D). These results indicate that EPAC signaling was modulated during the development of Dox-induced cardiotoxicity. 


\section{Doxorubicin-induced cardiotoxicity was prevented in EPAC1 knock-out mice}

Dox treatment was administered to both W'T and EPAC1 KO mice (Figure 6A) compared to injection with saline as control and analyzed 15 weeks after the last injection, when DCM was established. ${ }^{48}$ As observed in WT mice, ${ }^{48}$ a growth delay was observed in Dox treated EPAC1 KO mice in comparison to saline treated mice (Figure 6B). However, EPAC1 KO mice exhibited a preserved cardiac function after Dox treatment as evidenced by unaltered EF and LVEDV (Figure 6C \& 6D) suggesting a complete prevention of DCM development. Because cardiac function was preserved in EPAC1 $\mathrm{KO}$ mice, we tested the contractile function of isolated cardiomyocytes. Figure $6 \mathrm{G}$ shows that while cardiomyocytes treated with Dox presented reduced unloaded cell contraction (cell shortening), this decrease was prevented in EPAC1 KO mice. Because cell contraction is directly activated by the transient elevations in intracellular $\mathrm{Ca}^{2+}$, we measured the

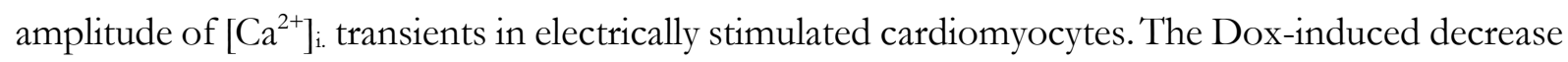
in $\left[\mathrm{Ca}^{2+}\right]_{\mathrm{i}}$ transient amplitude (peak F/Fo, Figure $6 \mathrm{E}$ ) and slowing down in $[\mathrm{Ca} 2+]$ i transient decay (Figure 6F), as previously reported, ${ }^{48}$ were prevented by the lack of EPAC1 (Figure 6E). The Dox induced decrease in SR $\mathrm{Ca}^{2+}$ load was also prevented in cardiomyocytes from EPAC1 KO mice (Figure 6H \& 6I), as well as SERCA2A expression (Figure 6J). These results demonstrate a complete prevention of Dox-induced cardiotoxicity by genetic deletion of EPAC1.

\section{EPAC1 inhibition enhanced the cytotoxic effect of Dox in various human cancer cell lines}

To test whether EPAC1 could be suggested as a valuable therapeutic target to limit Dox-induced cardiotoxicity, we evaluated whether its inhibition by CE3F4 compromised the anticancer efficacy of Dox. To this end, two cancer cell lines (MCF-7 human breast cancer and HeLa human cervical cancer) were selected due to their cancer origins usually treated by Dox. Dose response curves with increasing Dox concentrations in the absence or presence of CE3F4 $(10 \mu \mathrm{M})$ were performed on cancer cell lines and cell death (FDA) was measured (after $24 \mathrm{~h}$ ) using flow cytometry. As shown in Figure 7, Dox induced cell death in both cancer cell lines in a dose-dependent manner. 
bioRxiv preprint doi: https://doi.org/10.1101/2021.06.16.448655; this version posted June 17, 2021. The copyright holder for this preprint (which was not certified by peer review) is the author/funder. All rights reserved. No reuse allowed without permission.

Moreover, the percentage of dead cells was significantly increased in both cell lines in the presence of CE3F4 (Figure 7A \& 7B). Therefore, inhibition of EPAC1 by CE3F4 not only protects cardiac cells from Dox-induced toxicity but also enhances the anticancer efficacy of this anthracycline. 


\section{Discussion}

Doxorubicin is a potent chemotherapeutic agent widely used to treat a wide range of cancers. Nevertheless, cardiotoxicity is a well-known complication following treatment with anthracycline. Since decades, Dox-induced toxicity is considered to occur mostly/only through DNA damage, ROS generation, energetic distress and cell death (apoptosis, necrosis, etc.). However, noncanonical/alternative pathways are nowadays emerging and Dox-induced cardiotoxicity was recently proposed to occur through mechanisms other than those mediating its anticancer activity. ${ }^{19,20,52}$ Moreover, no widely-accepted therapeutic strategies to minimize Dox-induced cardiac injury have been established. The iron chelator Dexrazoxane is the only cardioprotectant that obtained a clinical authorization, but its application is limited and still controversial. ${ }^{23}$ In our work, we demonstrated for the first time that pharmacological inhibition (CE3F4) or genetic invalidation of EPAC1 prevented Dox-induced cardiotoxicity ex vivo and in vivo. We reported an up-regulation of expression and activity of EPAC1 following both ex vivo and in vivo Dox treatment. Moreover, specific EPAC1 inhibition with CE3F4, but not EPAC2 inhibition with ESI-05, reduced DNA damage, mitochondrial alterations and apoptosis elicited by Dox in cardiomyocytes, indicating that EPAC1, but not EPAC2, inhibition protected the heart against Dox-induced cardiotoxicity. This was confirmed in vivo in EPAC1 KO mice. Moreover, EPAC1 inhibition by CE3F4 not only protected cardiac cells, but also increased the toxicity of Dox against different cancer cell lines. Therefore, these results suggest that inhibition of EPAC1 by CE3F4 could be a promising strategy to prevent heart damage in anthracyclines-treated cancer patients.

Several evidences suggest that Dox and EPAC signaling pathways share common features and downstream effectors. ${ }^{35-37}$ Nonetheless, to the best of our knowledge, no direct link between these two pathways or interaction between their molecular actors and classical Dox-induced cardiotoxicity features has been reported so far. An ex vivo kinetic analysis revealed that Dox induces an increase in the expression of EPAC1 in the first hours after treatment ( $3 \mathrm{~h}-6 \mathrm{~h})$, followed by a 
downregulation of its protein level (16 h to $24 \mathrm{~h}$ ). Could be associated to global signal down regulation (Gs to Gi, decrease of $\beta$-AR1 expression) that could be seen following Dox exposure and in classical HF. ${ }^{53}$ Despite the drop in EPAC1 protein level, its activity remained elevated during the $24 \mathrm{~h}$ of Dox treatment. These results may find an explanation in the up-regulation of cAMP concentration induced by Dox in cardiomyocytes at least during the first $24 \mathrm{~h}$ as EPAC1 is directly activated by cAMP. Besides, we have previously demonstrated that EPAC signaling led to the activation of the pro-hypertrophic pathways calcineurin/NFAT and CaMKII/MEF2. ${ }^{25}$ Here, in response to Dox treatment, we found an alteration of the EPAC signaling with a downregulation of the calcineurin/NFAT activity but an increase of MEF2 activity, indicating in addition, a selective effect of Dox on EPAC signaling pathways. These results may explain why there is no reported case of hypertrophy in patients treated by Dox, as activation of both calcineurin/NFAT and CaMKII/MEF2 pathways are needed to launch the hypertrophic program. ${ }^{25}$ Altogether, our results indicate that Dox can regulate the protein level and activity of EPAC1 and its downstream effectors in cardiomyocytes.

The cell death pathway induced by Dox in our cardiac model is consistent with previous report. ${ }^{13}$ Indeed, Dox induces a mitochondrial caspase-dependent apoptosis characterized by DNA damage, $\mathrm{Ca}^{2+}$-dependent MPTP opening and mitochondrial membrane permeabilization, caspase activation, nuclear fragmentation and cell size reduction. By contrast to other studies, ${ }^{54,55}$ in our hands $1 \mu \mathrm{M}$ Dox did not induce necrosis in NRVM, as measured by propidium iodide staining. Nevertheless, treatment with higher doses of Dox (up to $10 \mu \mathrm{M}$ ) led to an increase of necrosis (up to $50 \%$, data not shown), indicating that induction of cardiac necrosis by Dox may be dosedependent.

The role of EPAC1 in cardiomyocyte apoptosis is still unclear owing to controversial reports. ${ }^{31-33,}$ ${ }^{38}$ Indeed, EPAC1 has been described as anti- or pro-apoptotic in the heart, depending on the type of cardiomyopathy and its mode of induction. For instance, EPAC1 was reported to be 
cardioprotective and to participate in antioxidant and anti-apoptotic effects of exendin-4, an agonist of the glucagon-like peptide-1 receptor. ${ }^{31}$ By contrast, EPAC1 ${ }^{-/}$mice are protected against cardiac damages induced by pressure overload, chronic catecholamine injection or ischemiareperfusion, ${ }^{32,38}$ suggesting a deleterious effect of EPAC1. Interestingly, such deleterious role of EPAC1 is not restricted to cardiac tissue. A recent study demonstrates that genetic deletion of EPAC1 or its inhibition by ESI-09 reduces nerve injury and inflammation, leading to allodynia upon treatment with the taxane paclitaxel. ${ }^{56}$ The protective/detrimental action of EPAC1 is thus not completely understood and might depend on the tissues and the pathophysiological mechanisms of the disease. Here, we have clearly shown with various approaches (ex vivo and in vivo, using pharmacological (CE3F4) and genetic approaches), that EPAC1 inhibition is cardioprotective in the context of Dox-induced apoptosis and cardiotoxicity.

Mechanistically, we demonstrated that EPAC1 inhibition prevents MPTP opening induced by Dox. Consistent with our observation, MPTP opening is known to result in mitochondrial membranes permeabilization, pro-apoptotic factors (cytochrome C, AIF, Smac/Diablo, etc.) release, activation of caspases and cell dismantling. ${ }^{57,58}$ In our model, Dox-induced opening of the MPTP was prevented by $\mathrm{Ca}^{2+}$ chelation and MCU inhibition. MCU is the critical protein of the inner mitochondrial membrane, which mediates the electrophoretic uptake of $\mathrm{Ca}^{2+}$ into the matrix. Given that $\mathrm{Ca}^{2+}$ is one of the most important inducers of MPTP opening, our data suggest that in cardiomyocytes, Dox treatment results in an elevation of the $\mathrm{Ca}^{2+}$ concentration in the mitochondrial matrix which triggers MPTP opening and subsequent apoptosis. Recently, it has been demonstrated that $\mathrm{EPAC1}^{-/}$mice are protected against myocardial ischemia/reperfusion injury. ${ }^{38}$ The EPAC1 activation leads to increased mitochondrial $\mathrm{Ca}^{2+}$ overload, which in turn promotes MPTP opening, pro-apoptotic factor release, caspase activation and cardiomyocyte death. The demonstration that EPAC1 inhibition prevents Dox-induced MPTP opening and cardiomyocyte death suggests that EPAC1 may play a similar deleterious role in Dox-associated 
cardiotoxicity and ischemia/reperfusion injury and that MPTP is a major downstream effector in the cardiac cell death signaling cascade regulated by EPAC1.

We found that Dox elicited mitochondrial dysfunction in cardiomyocytes, in agreement with previous report. ${ }^{59}$ Indeed, we found a downregulation of mitochondrial biogenesis, dynamic and function in cardiomyocytes exposed to Dox. Importantly, inhibition of EPAC1 by CE3F4 counteracted all the mitochondrial alterations induced by Dox. These results could be correlated with a previous study showing that during vascular injury, mitochondrial fission and cell proliferation were suppressed by inhibition of EPAC1 in vascular smooth muscle cells. ${ }^{60}$ Therefore, supporting the mitochondrial fusion process by inhibiting EPAC1 can help prevent Dox cardiotoxicity and vascular proliferative diseases.

One of the major mechanisms of Dox-induced cardiomyocytes death and mitochondria reprogramming involves TopII $\beta$. This gyrase is an enzyme that regulates DNA over-/underwinding by the formation of DNA/TopII cleavable complexes and generation of DNA double strand breaks. ${ }^{61}$ Thus, by its important role in replication and transcription, Topoisomerase II is of particular interest in cancer therapy. ${ }^{62}$. Recently, on the cardiac side, a new paradigm in Doxinduced cardiotoxicity has been put forward, conferring a central role to TopII $\beta$. Indeed, TopII $\beta$ is required for ROS generation, DNA damage and cell death induction, the three canonical mechanisms involved in Dox side effects. ${ }^{19}$ Here we showed that EPAC1 inhibition induced the downregulation of TopII $\beta$, indicating for the first time that EPAC1 modulates the expression of TopII $\beta$. As Dexrazoxane prevention against Dox-induced cardiotoxicity was mainly attributed to proteasomal degradation of TopII $\beta,{ }^{63}$ further investigation on the regulation of TopII $\beta$ expression by EPAC1 is therefore required. Additionally, our results showed that EPAC1 inhibition prevents Dox-induced formation of DNA-TopII $\beta$ cleavable complex, as evidenced by higher protein level of free TopII $\beta$, suggesting that EPAC1 inhibition blocks deleterious Dox effects in part through the TopII $\beta$ pathway. Thus, these results, in combination with others such as the recent example of 
$\mathrm{PI} 3 \mathrm{~K} \gamma,{ }^{20}$ show that molecular actors by their own are key components of the anthracyclines' cardiotoxicity and thus represents a new stream of thought in which signaling pathways are the first and major elements to consider both as mechanism and potential therapeutic targets.

Recent data have reported that EPAC1 could be essential to modulate cancer development and metastasis formation. ${ }^{41}$ In addition, inhibition of EPAC1 was proposed as a therapeutic strategy for the treatment of cancers such as melanoma, pancreatic or ovarian cancers. ${ }^{44,64-66}$ For instance, the genetic deletion of EPAC1 or the in vivo EPAC1 inhibition by ESI-09 decreases migration and metastasis of pancreatic cancer cells. ${ }^{43}$ Of note, in breast cancer cells, which are generally sensitive to Dox therapy, EPAC1 inhibition was shown to inhibit cell migration and induce apoptosis. ${ }^{67} \mathrm{In}$ the presented work, we demonstrated that inhibition of EPAC1 by CE3F4 increases Dox-induced cell death in different human cancer cells lines, including breast cancer cells. Therefore, our data show that EPAC1 inhibition not only protects cardiac cells from Dox-induced toxicity but also enhances the sensitivity of cancer cells to Dox. Similarly, PI3K $\gamma$ blockade ${ }^{20}$ or the novel agent named biotin-conjugated ADTM analog $(\mathrm{BAA})^{52}$ were shown to prevent Dox-induced cardiotoxicity and to synergize with its antitumor activity against breast cancer. Therefore, the identification of new promising chemical compound, such as BAA or CE3F4, could be the starting point to the next therapeutic treatments that would protect patients from acute and chronic cardiotoxicity of Dox without altering its cytotoxicity towards cancer cells.

In conclusion, EPAC1 is identified for the first time as a new regulator of Dox-induced toxicity in cardiac cells. In response to Dox, the pharmacological inhibition of EPAC1 by CE3F4 recapitulated EPAC1 knock-out phenotype, suggesting the potential therapeutic efficacy of this EPAC1 inhibitor to alleviate Dox-associated side-effects in the heart, while maintaining, or enhancing anticancer effect. Thus, EPAC1 inhibition represents a promising therapeutic strategy both to prevent Dox cardiotoxicity and to enhance its antitumoral activity. 


\section{Acknowledgments}

We are grateful to Dr E. Hirsch and Dr A. Ghigo (University of Torino, Italy) and Dr D. Hilfiker-Kleiner (Hannover Medical School, Germany) for providing us with cancer cell lines, and to V. Domergue and the animal facility (IPSIT platform) for animal housing.

\section{Sources of funding}

This works was supported by grants from Agence National de la Recherche (ANR) grants (ANR-13-BSV1-0023 and ANR-15-CE14-0005), LabEx LERMIT (ANR-10-LABX-0033), Departement hospitalo Universitaire (DHU) TORINO, Leducq Foundation for Cardiovascular Research (19CVD02), and INSERM. AL was recipient of a Lefoulon Delalande fellowship.

\section{Disclosures}

None

\section{Supplemental Materials}

Expanded Methods

References 30 to 71

Supplemental Table 1

Supplemental Figures 1 to 3 


\section{References}

1. Damiani RM, Moura DJ, Viau CM, Caceres RA, Henriques JA and Saffi J. Pathways of cardiac toxicity: comparison between chemotherapeutic drugs doxorubicin and mitoxantrone. Archives of toxicology. 2016;90:2063-76.

2. McGowan JV, Chung R, Maulik A, Piotrowska I, Walker JM and Yellon DM. Anthracycline Chemotherapy and Cardiotoxicity. Cardiovascular drugs and therapy. 2017;31:63-75.

3. Swain SM, Whaley FS and Ewer MS. Congestive heart failure in patients treated with doxorubicin: a retrospective analysis of three trials. Cancer. 2003;97:2869-79.

4. Hurria A. Embracing the complexity of comorbidity. Journal of clinical oncology : official journal of the American Society of Clinical Oncology. 2011;29:4217-8.

5. Lipshultz SE, Colan SD, Gelber RD, Perez-Atayde AR, Sallan SE and Sanders SP. Late cardiac effects of doxorubicin therapy for acute lymphoblastic leukemia in childhood. The New England journal of medicine. 1991;324:808-15.

6. Lipshultz SE, Scully RE, Lipsitz SR, Sallan SE, Silverman LB, Miller TL, Barry EV, Asselin BL, Athale U, Clavell LA, Larsen E, Moghrabi A, Samson Y, Michon B, Schorin MA, Cohen HJ, Neuberg DS, Orav EJ and Colan SD. Assessment of dexrazoxane as a cardioprotectant in doxorubicin-treated children with high-risk acute lymphoblastic leukaemia: long-term follow-up of a prospective, randomised, multicentre trial. The Lancet Oncology. 2010;11:950-61.

7. Renu K, V GA, P BT and Arunachalam S. Molecular mechanism of doxorubicin-induced cardiomyopathy - An update. European journal of pharmacology. 2018;818:241-253.

8. L'Ecuyer T, Sanjeev S, Thomas R, Novak R, Das L, Campbell W and Heide RV. DNA damage is an early event in doxorubicin-induced cardiac myocyte death. American journal of physiology Heart and circulatory physiology. 2006;291:H1273-80.

9. Cappetta D, De Angelis A, Sapio L, Prezioso L, Illiano M, Quaini F, Rossi F, Berrino L, Naviglio S and Urbanek K. Oxidative Stress and Cellular Response to Doxorubicin: A Common 
bioRxiv preprint doi: https://doi.org/10.1101/2021.06.16.448655; this version posted June 17, 2021. The copyright holder for this preprint (which was not certified by peer review) is the author/funder. All rights reserved. No reuse allowed without permission.

Factor in the Complex Milieu of Anthracycline Cardiotoxicity. Oxidative medicine and cellular longevity. 2017;2017:1521020.

10. Rochette L, Guenancia C, Gudjoncik A, Hachet O, Zeller M, Cottin Y and Vergely C. Anthracyclines/trastuzumab: new aspects of cardiotoxicity and molecular mechanisms. Trends in pharmacological sciences. 2015;36:326-48.

11. Tokarska-Schlattner M, Zaugg M, Zuppinger C, Wallimann T and Schlattner U. New insights into doxorubicin-induced cardiotoxicity: the critical role of cellular energetics. Journal of molecular and cellular cardiology. 2006;41:389-405.

12. Liu J, Mao W, Ding B and Liang CS. ERKs/p53 signal transduction pathway is involved in doxorubicin-induced apoptosis in $\mathrm{H} 9 \mathrm{c} 2$ cells and cardiomyocytes. American journal of physiology Heart and circulatory physiology. 2008;295:H1956-65.

13. Zhang YW, Shi J, Li YJ and Wei L. Cardiomyocyte death in doxorubicin-induced cardiotoxicity. Archivum immunologiae et therapiae experimentalis. 2009;57:435-45.

14. Casey TM, Arthur PG and Bogoyevitch MA. Necrotic death without mitochondrial dysfunction-delayed death of cardiac myocytes following oxidative stress. Biochimica et biophysica acta. 2007;1773:342-51.

15. Goormaghtigh E, Huart P, Praet M, Brasseur R and Ruysschaert JM. Structure of the adriamycin-cardiolipin complex. Role in mitochondrial toxicity. Biophysical chemistry. 1990;35:24757.

16. Guo J, Guo Q, Fang H, Lei L, Zhang T, Zhao J and Peng S. Cardioprotection against doxorubicin by metallothionein Is associated with preservation of mitochondrial biogenesis involving PGC-1alpha pathway. European journal of pharmacology. 2014;737:117-24.

17. Kavazis AN, Morton AB, Hall SE and Smuder AJ. Effects of doxorubicin on cardiac muscle subsarcolemmal and intermyofibrillar mitochondria. Mitochondrion. 2017;34:9-19.

18. Dorn GW, 2nd, Vega RB and Kelly DP. Mitochondrial biogenesis and dynamics in the developing and diseased heart. Genes \& development. 2015;29:1981-91. 
19. Zhang S, Liu X, Bawa-Khalfe T, Lu LS, Lyu YL, Liu LF and Yeh ET. Identification of the molecular basis of doxorubicin-induced cardiotoxicity. Nature medicine. 2012;18:1639-42.

20. Li M, Sala V, De Santis MC, Cimino J, Cappello P, Pianca N, Di Bona A, Margaria JP, Martini M, Lazzarini E, Pirozzi F, Rossi L, Franco I, Bornbaum J, Heger J, Rohrbach S, Perino A, Tocchetti CG, Lima BHF, Teixeira MM, Porporato PE, Schulz R, Angelini A, Sandri M, Ameri P, Sciarretta S, Lima-Junior RCP, Mongillo M, Zaglia T, Morello F, Novelli F, Hirsch E and Ghigo A. Phosphoinositide 3-Kinase Gamma Inhibition Protects from Anthracycline Cardiotoxicity and Reduces Tumor Growth. Circulation. 2018.

21. Swain SM, Whaley FS, Gerber MC, Weisberg S, York M, Spicer D, Jones SE, Wadler S, Desai A, Vogel C, Speyer J, Mittelman A, Reddy S, Pendergrass K, Velez-Garcia E, Ewer MS, Bianchine JR and Gams RA. Cardioprotection with dexrazoxane for doxorubicin-containing therapy in advanced breast cancer. Journal of clinical oncology : official journal of the American Society of Clinical Oncology. 1997;15:1318-32.

22. Reichardt P, Tabone MD, Mora J, Morland B and Jones RL. Risk-benefit of dexrazoxane for preventing anthracycline-related cardiotoxicity: re-evaluating the European labeling. Future oncology. 2018.

23. Tebbi CK, London WB, Friedman D, Villaluna D, De Alarcon PA, Constine LS, Mendenhall NP, Sposto R, Chauvenet A and Schwartz CL. Dexrazoxane-associated risk for acute myeloid leukemia/myelodysplastic syndrome and other secondary malignancies in pediatric Hodgkin's disease. Journal of clinical oncology : official journal of the American Society of Clinical Oncology. 2007;25:493-500.

24. Metrich M, Lucas A, Gastineau M, Samuel JL, Heymes C, Morel E and Lezoualc'h F. Epac mediates beta-adrenergic receptor-induced cardiomyocyte hypertrophy. Circulation research. 2008;102:959-65. 
25. Morel E, Marcantoni A, Gastineau M, Birkedal R, Rochais F, Garnier A, Lompre AM, Vandecasteele G and Lezoualc'h F. cAMP-binding protein Epac induces cardiomyocyte hypertrophy. Circulation research. 2005;97:1296-304.

26. de Rooij J, Zwartkruis FJ, Verheijen MH, Cool RH, Nijman SM, Wittinghofer A and Bos JL. Epac is a Rap1 guanine-nucleotide-exchange factor directly activated by cyclic AMP. Nature. 1998;396:474-7.

27. Kawasaki H, Springett GM, Mochizuki N, Toki S, Nakaya M, Matsuda M, Housman DE and Graybiel AM. A family of cAMP-binding proteins that directly activate Rap1. Science. 1998;282:2275-9.

28. Pereira L, Ruiz-Hurtado G, Morel E, Laurent AC, Metrich M, Dominguez-Rodriguez A, Lauton-Santos S, Lucas A, Benitah JP, Bers DM, Lezoualc'h F and Gomez AM. Epac enhances excitation-transcription coupling in cardiac myocytes. Journal of molecular and cellular cardiology. 2012;52:283-91.

29. Cazorla O, Lucas A, Poirier F, Lacampagne A and Lezoualc'h F. The cAMP binding protein Epac regulates cardiac myofilament function. Proceedings of the National Academy of Sciences of the United States of America. 2009;106:14144-9. 
Figure legends

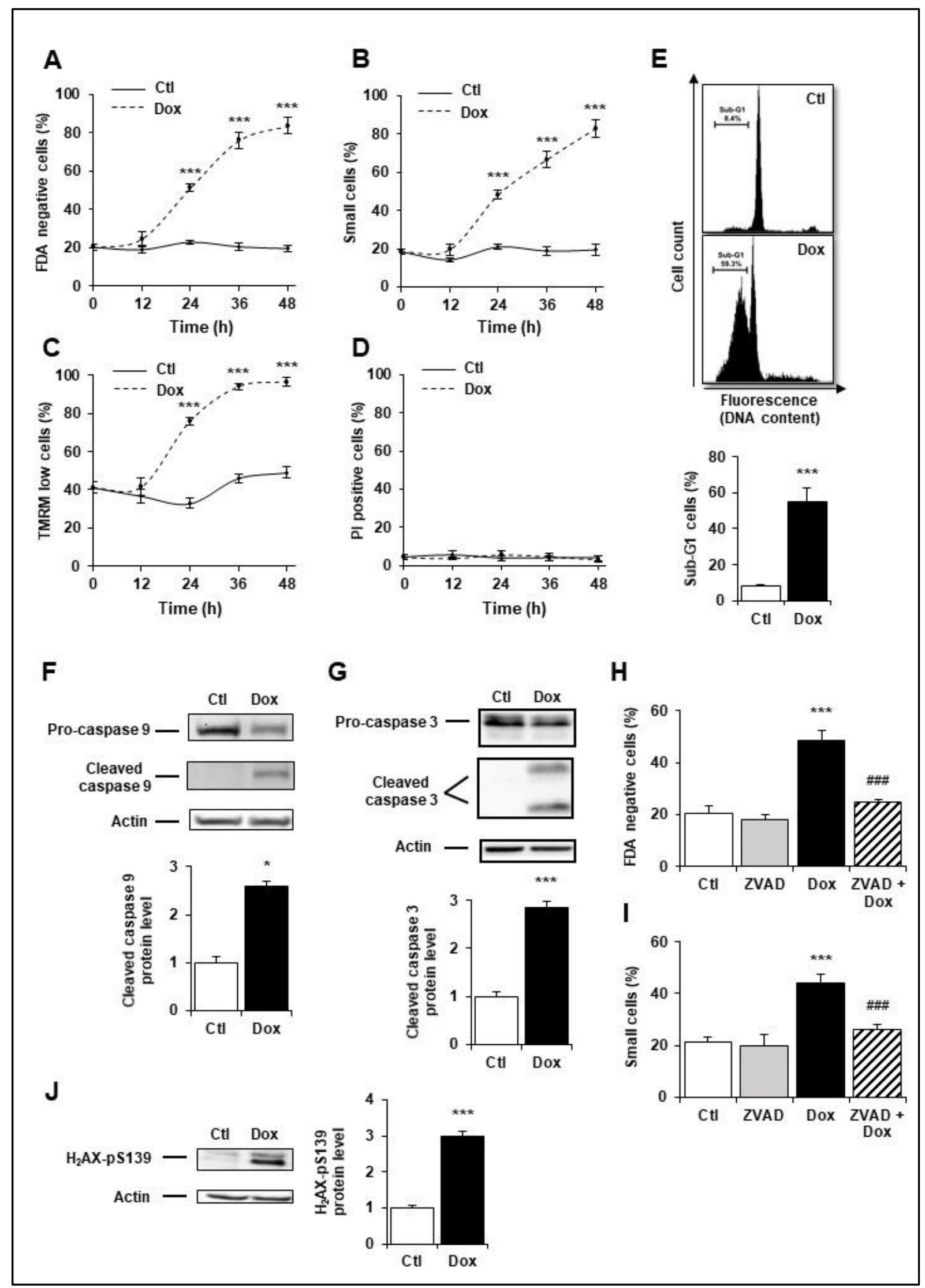


Figure 1. Doxorubicin induced DNA damages and the mitochondrial pathway of apoptosis in cardiac myocytes

(A to D) Cell death markers were recorded by flow cytometry in NRVM treated or not with Dox $(1 \mu \mathrm{M})$ for $12 \mathrm{~h}, 24 \mathrm{~h}, 36 \mathrm{~h}$, and $48 \mathrm{~h}$. Results are presented as mean \pm S.E.M. $(\mathrm{n}=12) .{ }^{*} * * \mathrm{P}<0.001$ vs. control. (A) Percentages of dead cells (FDA negative cells) measured by FDA assay. (B) Percentages of small cells obtained by gating the cell population with decrease forward scatter signal. (C) Percentages of cells with decreased $\Delta \Psi \mathrm{m}$ recorded after TMRM staining. (D) Necrosis was assessed using PI probe and the percentages of cells with permeabilized plasma membrane (PI positive cells) are presented. (E) NRVM were left untreated $(\mathrm{Ctl})$ or treated with Dox $(1 \mu \mathrm{M})$ for $24 \mathrm{~h}$ and the percentages of cells with fragmented DNA (Sub-G1 DNA content) were recorded by flow cytometry and presented as mean \pm S.E.M. ( $\mathrm{n}=4)$. ${ }^{* * *} \mathrm{P}<0.001$ vs. control. NRVM were treated or not with Dox $(1 \mu \mathrm{M})$ for $16 \mathrm{~h}$ and the levels of cleaved-caspase 9 (F) or cleaved-caspase 3 (G) were detected by western blot. Actin was used as a loading control and relative protein levels are presented in bar graphs (mean \pm S.E.M., $\mathrm{n}=4$ for caspase 9 and $\mathrm{n}=10$ for caspase 3 ). $* \mathrm{P}<0.05$, ***P $<0.001$ vs. control. (H-I) NRVM were treated or not with Dox $(1 \mu \mathrm{M})+/$ - the general caspase inhibitor ZVAD-fmk (50 $\mu \mathrm{M})$ for $24 \mathrm{~h}$. The percentage of dead cells $\mathbf{( H )}$ and small cells (I) were recorded. Results are expressed as the percentage of dead cells (FDA negative cells) and small cells (mean \pm S.E.M., $\mathrm{n}=8$ ). ${ }^{* * *} \mathrm{P}<0.001$ vs. control, \#\#\#P<0.001 vs. Dox alone. (J) NRVM were left untreated $(\mathrm{Ctl})$ or treated with Dox $(1 \mu \mathrm{M})$ for $16 \mathrm{~h}$ and the level of the DNA damage marker phosphorylated histone $\mathrm{H}_{2} \mathrm{AX}\left(\mathrm{H}_{2} \mathrm{AX}-\mathrm{pS}_{139}\right)$ was analyzed by Western blot. Actin was used as a loading control. Relative protein levels are presented in bar graphs (mean \pm S.E.M., $n=6$ ). $* * * \mathrm{P}<0.001$ vs. control. 
A
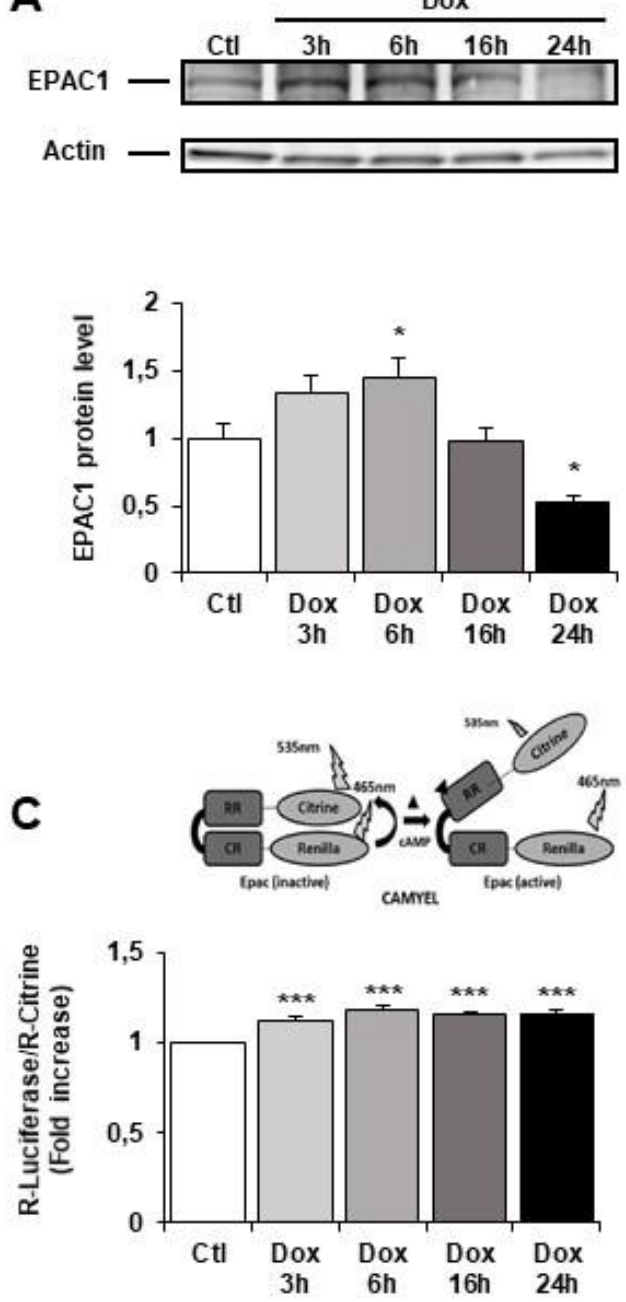

$\mathbf{E}$

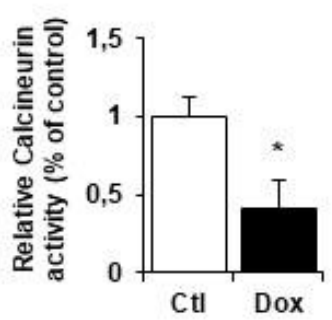

G

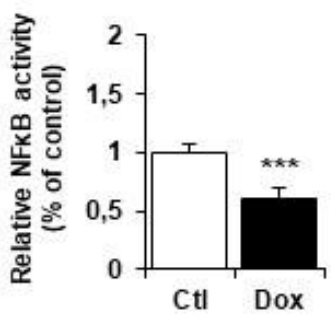

B
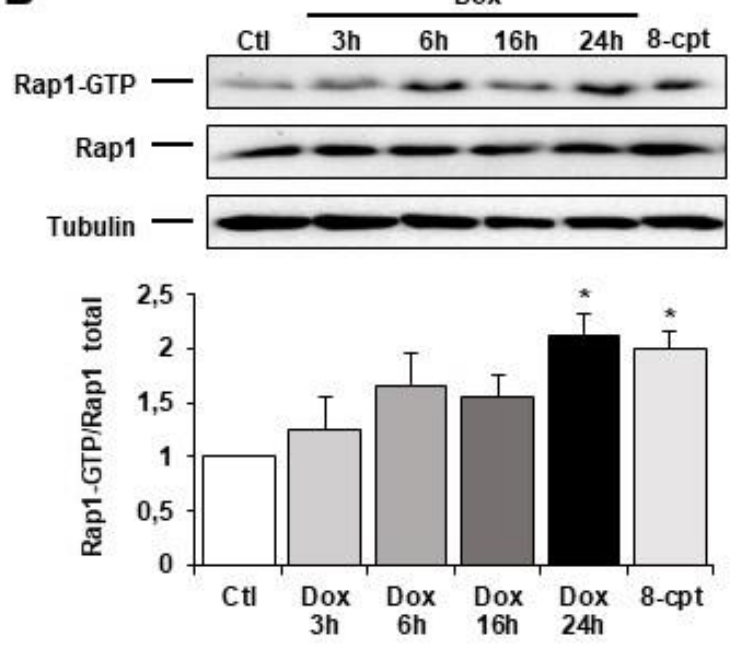

D

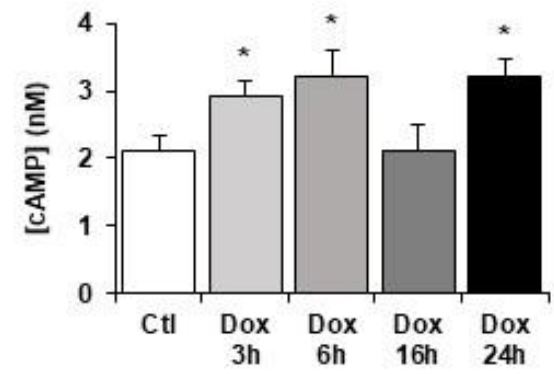

$\mathbf{F}$

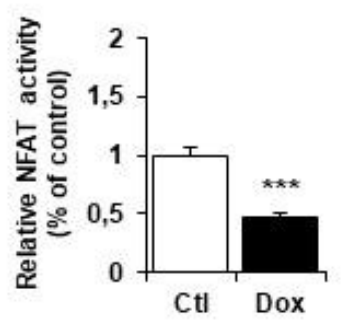

H

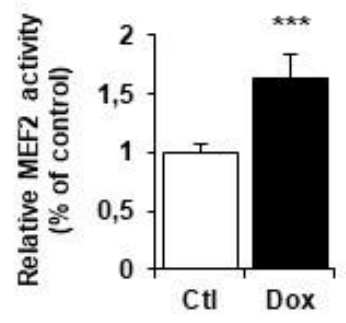

Figure 2. Dox modulated cAMP-EPAC1 pathway in cardiac cells 
(A) NRVM were left untreated or treated with $1 \mu \mathrm{M}$ Dox for $3 \mathrm{~h}, 6 \mathrm{~h}, 16 \mathrm{~h}$ and $24 \mathrm{~h}$ and the level of EPAC1 protein was detected by western blot. Actin was used as a loading control. Relative protein levels are presented in bar graphs (mean \pm S.E.M., $n=7$ ). $* \mathrm{P}<0.05$ vs. control. (B) NRVM were left untreated or treated with Dox $(1 \mu \mathrm{M})$ for $3 \mathrm{~h}, 6 \mathrm{~h}, 16 \mathrm{~h}$ and $24 \mathrm{~h}$ or with the EPAC activator 8-CPT $(10 \mu \mathrm{M})$ for $3 \mathrm{~h}$. GTP-Activated form of RAP1 was analyzed by pull-down assay. RAP1-GTP/RAP1 total ratios are expressed in bar graphs as mean \pm S.E.M. (n=3). (C-D) NRVM were left untreated or treated with Dox $(1 \mu \mathrm{M})$ for 3 h, 6 h, 16 h and 24 h. (C) CAMYEL-based EPAC1 BRET sensor was used to measure EPAC1 activation. The BRET ratio was calculated as the ratio of the Renilla luciferase emission signal to that of citrine-cp (means \pm S.E.M, $n=3$ ). (D) The concentration of cAMP (nM) was monitored by cAMP dynamic 2 kit (means \pm S.E.M., $n=4$ ). $* \mathrm{P}<0.05$ vs. control). (E) NRVM were left untreated or treated with Dox $(1 \mu \mathrm{M})$ for $24 \mathrm{~h}$ and Calcineurin activity was measured (means \pm S.E.M., $n=3$ ). ${ }^{*} \mathrm{P}<0.05$ vs. control. (F to $\left.\mathbf{H}\right) \mathrm{NRVM}$ were transfected with NFAT-luc (F), NFxB-luc $(\mathbf{G})$ or MEF2-luc $(\mathbf{H})$ vectors and treated or not with Dox $(1 \mu \mathrm{M})$ for $24 \mathrm{~h}$. Two days after transfection, cells were assayed for Luciferase activity and normalized to Renilla luciferase transcriptional activity (means \pm S.E.M., $\mathrm{n}=3$ ). ${ }^{* * *} \mathrm{P}<0.001$ vs. control. 


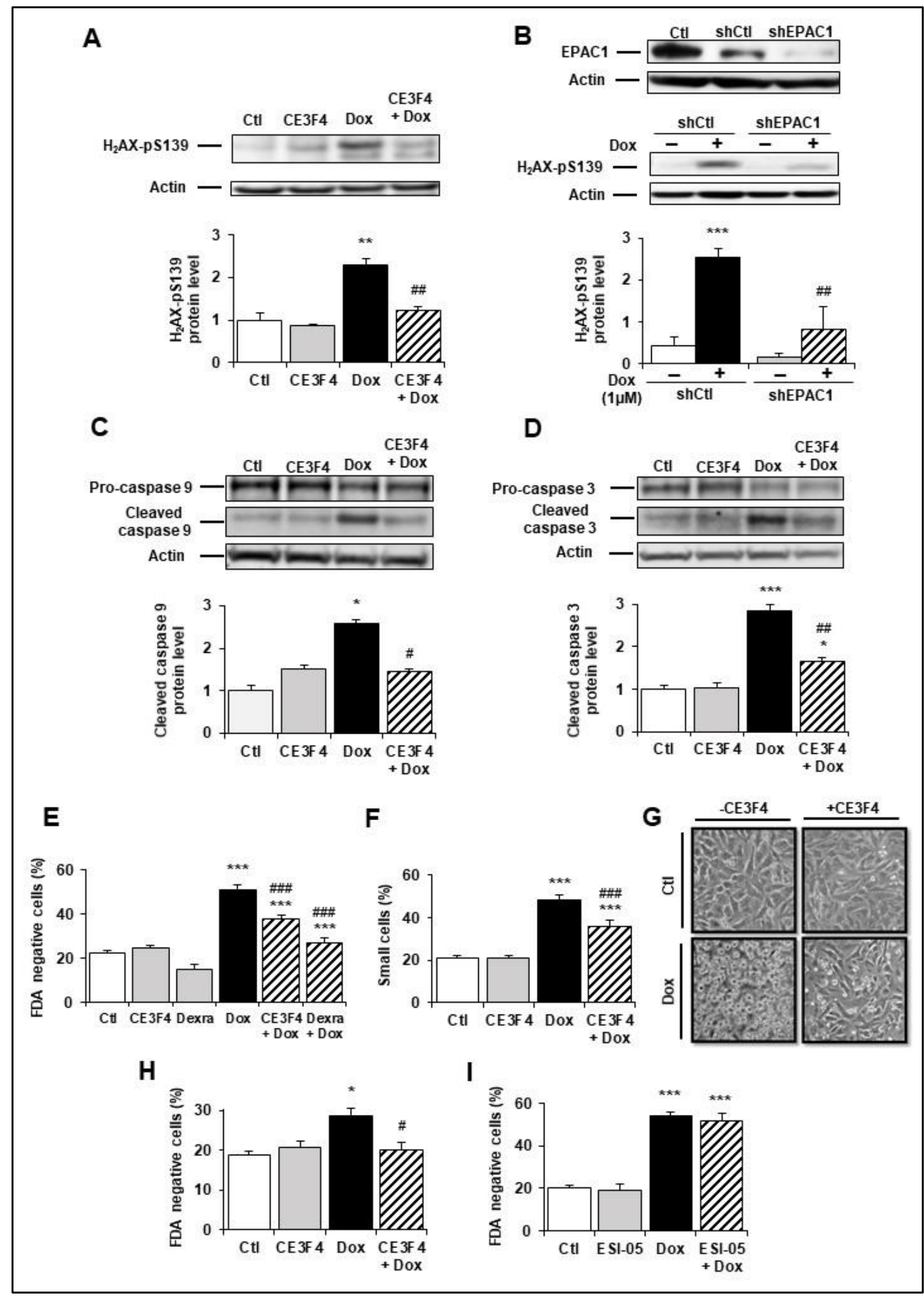

Figure 3. Pharmacological inhibition of EPAC1 by CE3F4 protected cardiomyocytes from Dox-induced DNA damage, caspase activation and cell death 
(A) NRVM were left untreated or treated with Dox $(1 \mu \mathrm{M})+/$ - the specific EPAC1 inhibitor CE3F4 $(10 \mu \mathrm{M})$ for $16 \mathrm{~h}$ and the level of the DNA damage marker $\mathrm{H}_{2} \mathrm{AX}-\mathrm{pS}_{139}$ was analyzed by western blot. Actin was used as a loading control. Relative protein levels are presented in bar graphs (mean \pm S.E.M., $\mathrm{n}=6$ ). ${ }^{*} * \mathrm{P}<0.01$ vs. control, \#\#P<0.01 vs. Dox alone. (B) NRVM were transfected with Control (shCtl) or EPAC1 (shEPAC1) shRNA for $12 \mathrm{~h}$ before treatment with Dox for 16 h. The relative levels of EPAC1 and $\mathrm{H}_{2} \mathrm{AX}-\mathrm{pS}_{139}$ were measured by immunoblotting with Actin as a loading control (mean \pm S.E.M., $\mathrm{n}=3$ ). ${ }^{* * *} \mathrm{P}<0.001$ vs. shCtl, \#\#P<0.01 vs. shCtl+Dox. (C-D) NRVM were left untreated or treated with Dox $(1 \mu \mathrm{M})+/$ - CE3F4 $(10 \mu \mathrm{M})$ for $16 \mathrm{~h}$ and the levels of cleaved-caspase 9 (C) and cleaved-caspase 3 (D) were detected by western blot. Actin was used as a loading control and relative protein levels are presented in bar graphs (means \pm S.E.M., $\mathrm{n}=4$ for caspase 9 and $\mathrm{n}=10$ for caspase 3 ). $* \mathrm{P}<0.05,{ }^{*} * * \mathrm{P}<0.001$ vs. control, $\# \mathrm{P}<0.05$, \#\#P<0.01 vs. Dox alone. (E-F) NRVM were treated or not with Dox $(1 \mu \mathrm{M})+/-$ CE3F4 $(10 \mu \mathrm{M})$ for $24 \mathrm{~h}$ and analyzed by flow cytometry. Results in bar graphs are expressed as

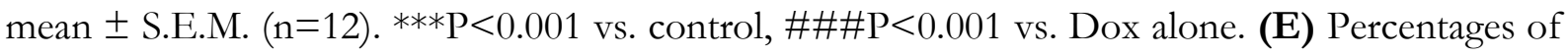
dead cells (FDA negative cells) (F) Percentages of small cells. (G) Representative micrographs of NRVM left untreated or treated with Dox $(1 \mu \mathrm{M})+/$ - Ce3F4 $(10 \mu \mathrm{M})$ for $24 \mathrm{~h}$. (H) Freshly isolated ARVM were treated or not with Dox $(1 \mu \mathrm{M})+$ - CE3F4 $(10 \mu \mathrm{M})$ and cell death was determined. The percentage of dead cells (FDA negative cells) is presented in bar graphs (means \pm S.E.M., $\mathrm{n}=4) . * \mathrm{P}<0.05$ vs. control, $\# \mathrm{P}<0.05$ vs. Dox alone. (I) The percentages of dead cells (FDA negative cells) were assessed in NRVM left untreated or treated with Dox $(1 \mu \mathrm{M})+/$ - the specific EPAC2 inhibitor ESI-05 $(1 \mu \mathrm{M})$ and presented as means \pm S.E.M. $(\mathrm{n}=6) . * * * \mathrm{P}<0.001$ vs. control, \#\#\#P<0.001 vs. Dox alone. 
A

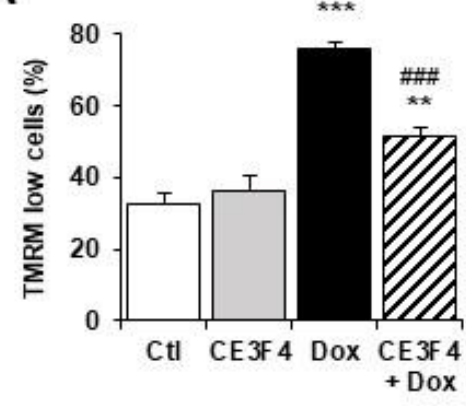

C

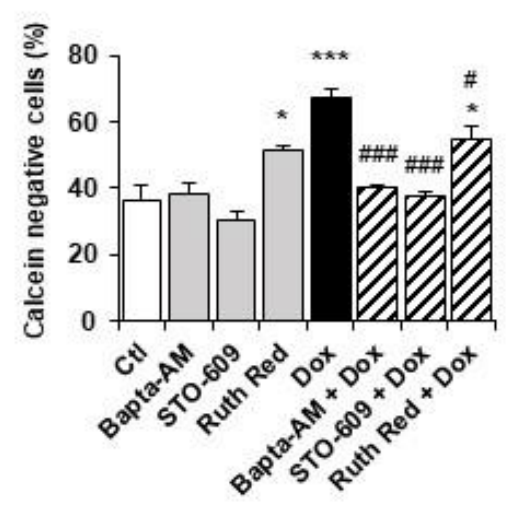

$\mathbf{F}$

D
B

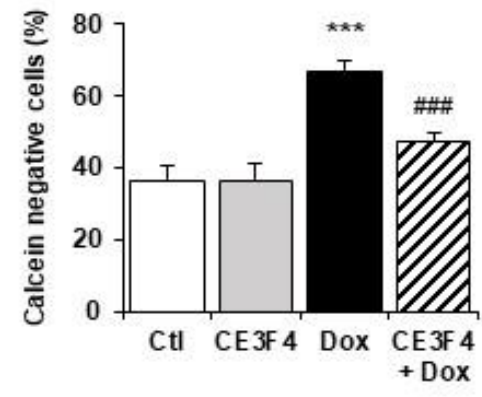

E
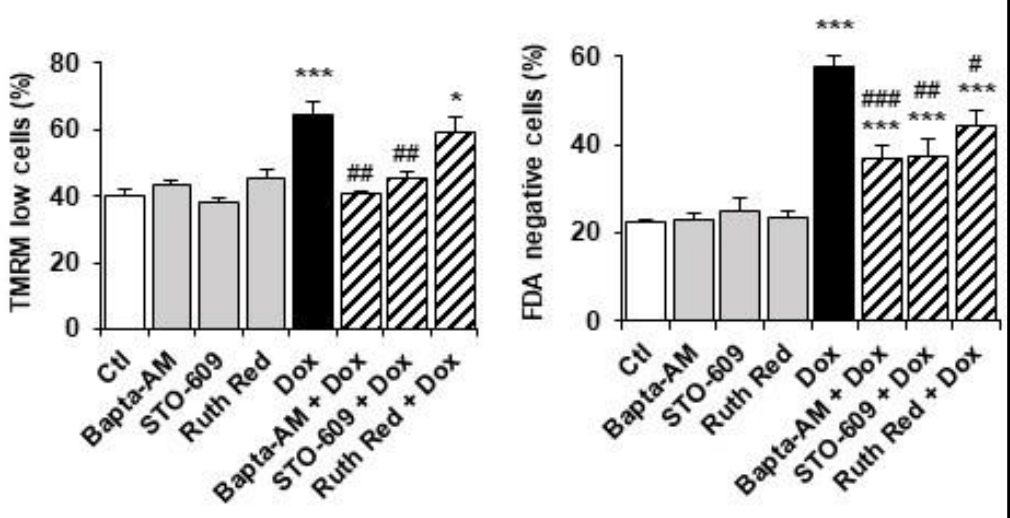

G
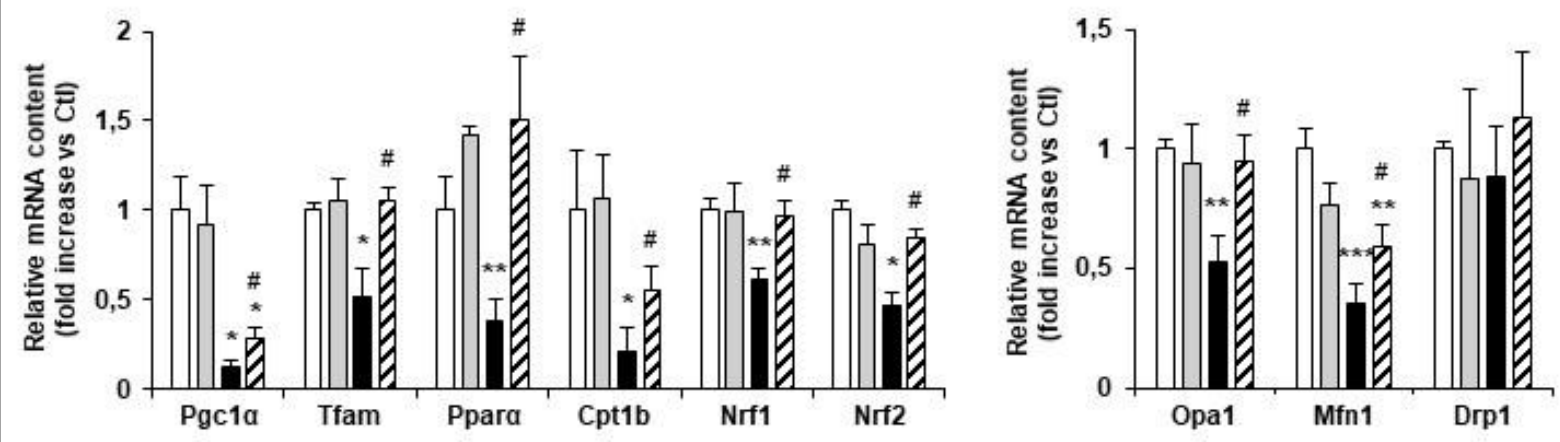

H

I
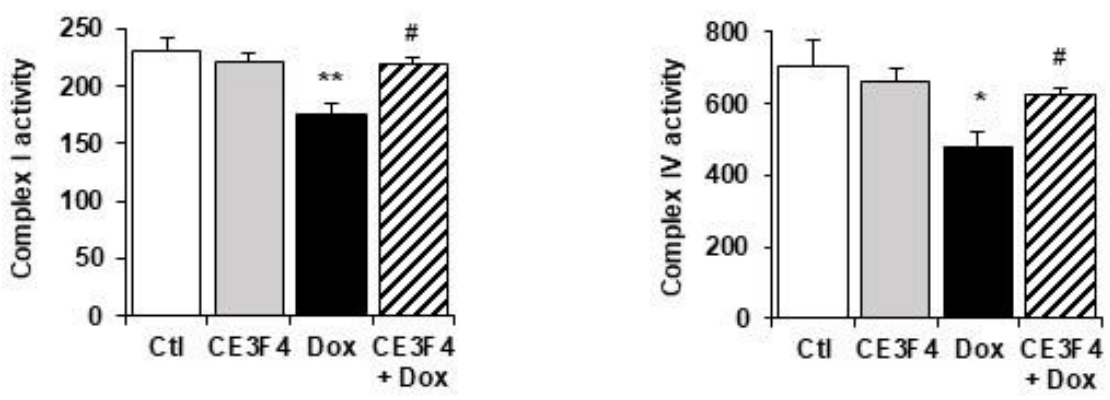

Figure 4. EPAC1 inhibition by CE3F4 reduced Dox-induced mitochondrial alterations 
(A-B) NRVM were left untreated or treated with Dox $(1 \mu \mathrm{M})+/-$ CE3F4 $(10 \mu \mathrm{M})$ for $24 \mathrm{~h}$. Results are expressed as means \pm S.E.M. $(\mathrm{n}=4) .{ }^{* *} \mathrm{P}<0.01,{ }^{* * *} \mathrm{P}<0.001$ vs. control, $\# \# \# \mathrm{P}<0.001$ vs. Dox alone (A) TMRM staining was used to assess the percentages of cells with decreased $\Delta \Psi \mathrm{m}$. (B) Calcein-Cobalt assay was used to record MPTP opening (Calcein negative cells). (C to E) NRVM were treated or not with Dox $(1 \mu \mathrm{M})+/$ - the calcium chelator Bapta-AM $(20 \mu \mathrm{M})$, or the CAMKK $\beta$ inhibitor STO-609 $(25 \mu \mathrm{M})$ or the MCU inhibitor Ruthenium Red $(25 \mu \mathrm{M}) . \Delta \Psi \mathrm{m}$ loss (C), MPTP opening (D) and cell death (E) were assessed as already described. Results are presented as means \pm S.E.M. ( $\mathrm{n}=4$ for MPTP opening and TMRM and $\mathrm{n}=8$ for cell death). $* \mathrm{P}<0.05, * * * \mathrm{P}<0.001$ vs. control, \#P<0.05, \#\#P<0.01, \#\#\#P<0.001 vs. Dox alone. (F to I) NRVM were left untreated or treated with Dox $(1 \mu \mathrm{M})$ and +/- CE3F4 $(10 \mu \mathrm{M})$ for 16 h. Relative mRNA levels of mitochondrial biogenesis- (F) and mitochondrial dynamic-related markers (G) were quantified by RT-qPCR and expressed as fold increase over untreated controls (means \pm S.E.M., $\mathrm{n}=4$ ). ${ }^{*} \mathrm{P}<0.05,{ }^{*} * \mathrm{P}<0.01$ vs. control, $\# \mathrm{P}<0.05$ vs. Dox alone. Activity of the mitochondrial respiratory complex I (H) and complex IV (I) are presented in the bar graphs as means \pm S.E.M. ( $\mathrm{n}=5) . * \mathrm{P}<0.05,{ }^{*} * \mathrm{P}<0.01$ vs. control, \#P<0.05 vs. Dox alone. 
A

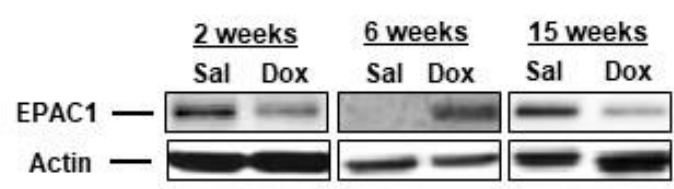

B

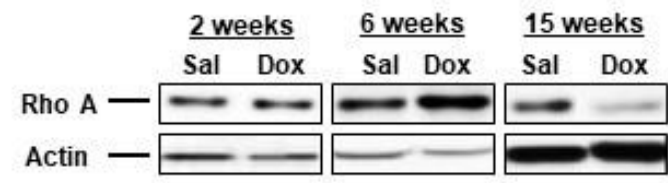

C

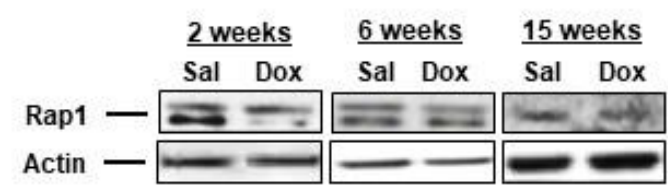

D

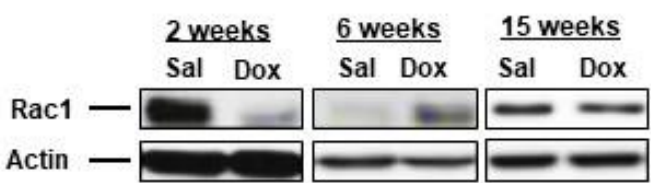

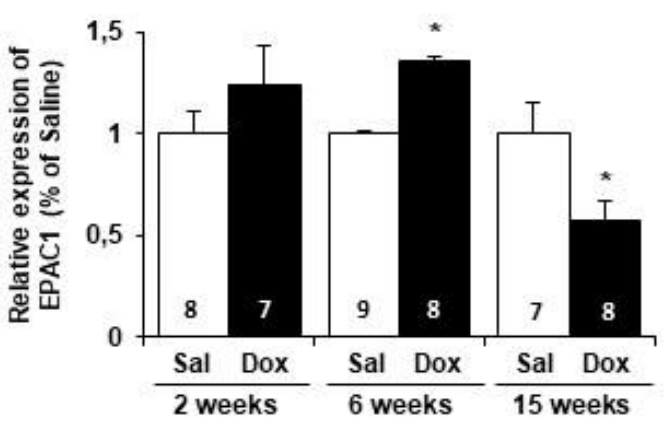
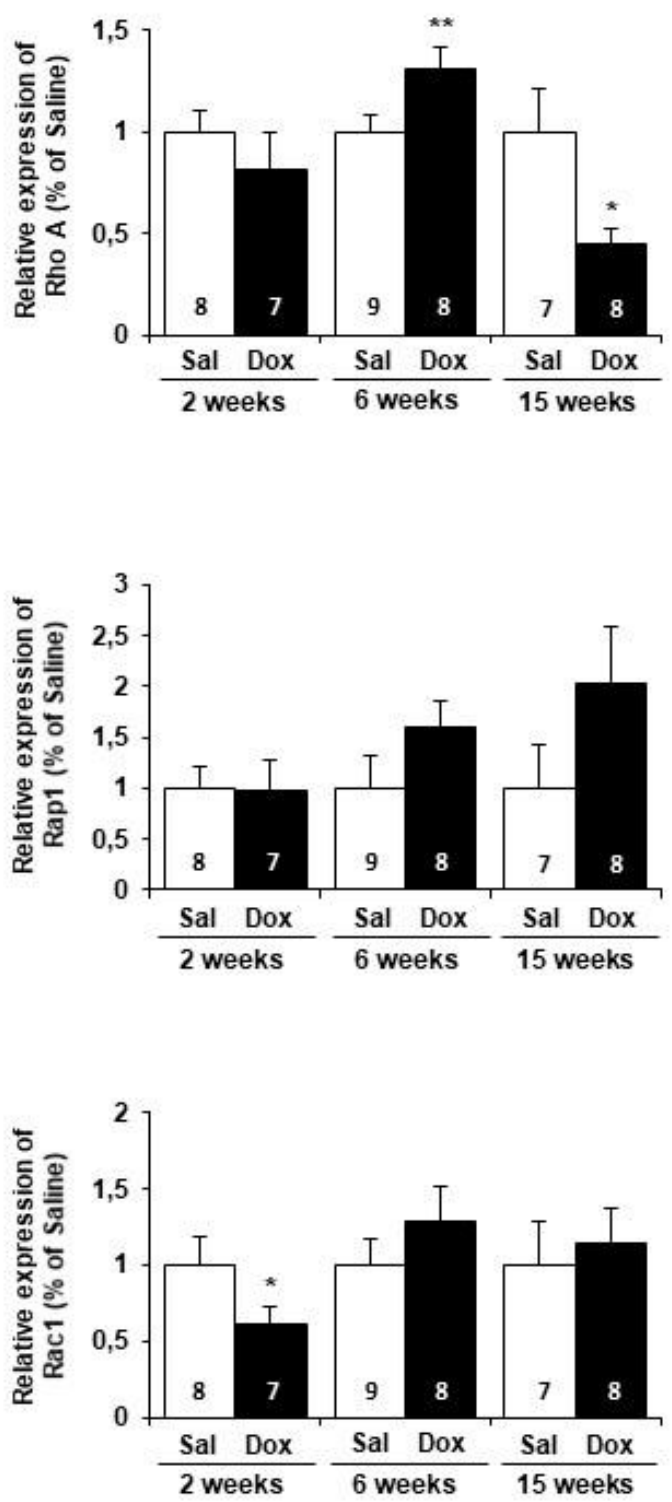

Figure 5. Dox induced a dilated cardiomyopathy in C57BL6 mice 15 weeks post-treatment with global alteration of EPAC1 signaling 
(A to D) C57BL/ 6 mice were injected (i.v) three times with Saline Solution (Sal) or Doxorubicin (Dox) at $4 \mathrm{mg} / \mathrm{kg}$ for each injection (12 mg/ $\mathrm{kg}$ cumulative dose). The levels of EPAC1 (A), RhoA (B), Rap1 (C) and Rac1 (D) proteins were determined by western blot at 2, 6 and 15 weeks after the last injection. Actin was used as a loading control. Relative protein levels are presented in bar graphs $* \mathrm{P}<0.05$ vs. Saline. The number of saline or dox-treated mice is indicated in the bars of the graphs. 


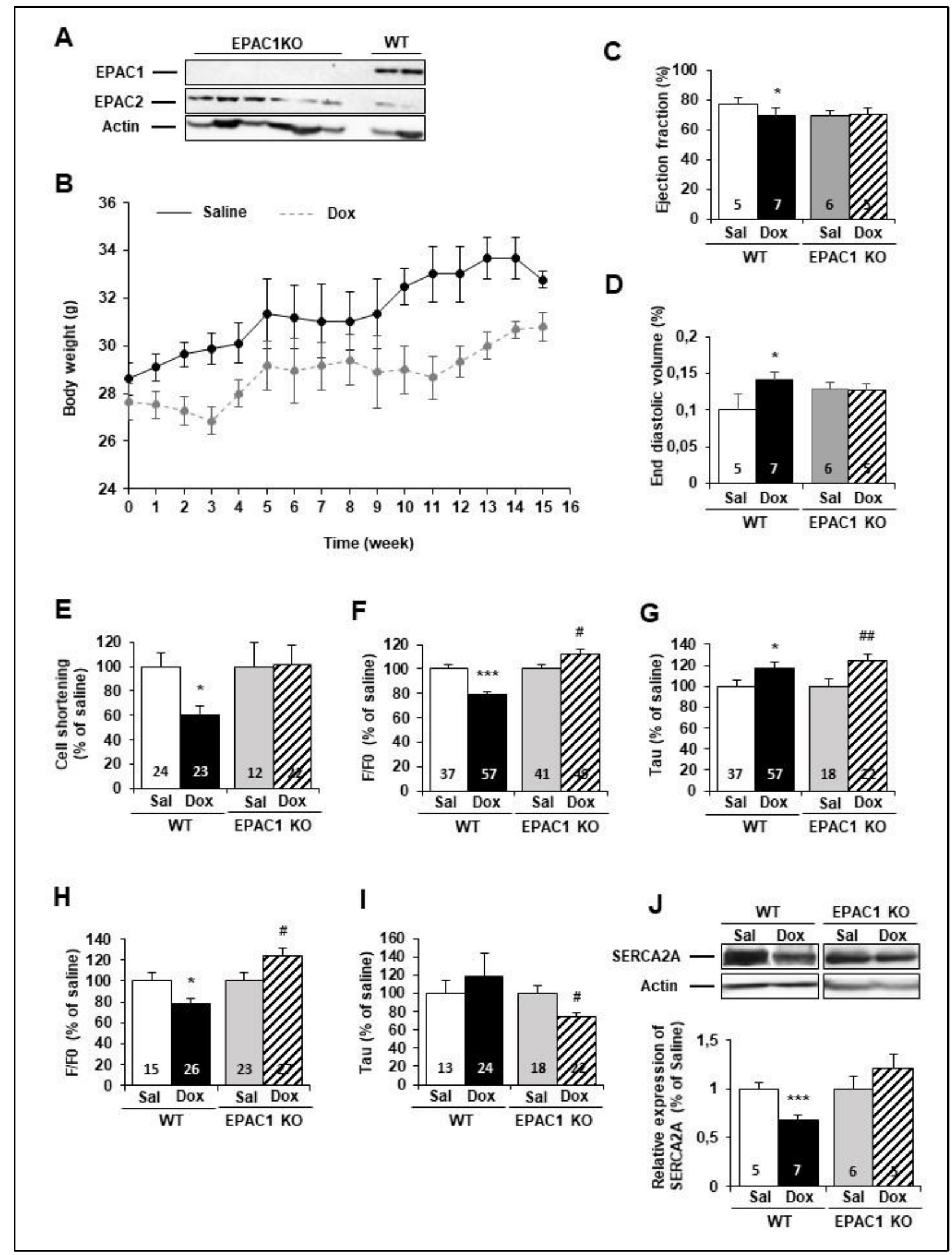

Figure 6. Doxorubicin-induced cardiotoxicity was prevented in EPAC1 knock-out mice

WT and EPAC1 KO mice were injected (i.v) three times with Saline Solution (Sal) or Doxorubicin (Dox) at $4 \mathrm{mg} / \mathrm{kg}$ for each injection $(10 \pm 2 \mathrm{mg} / \mathrm{kg}$ cumulative dose). Analysis were performed at 
15 weeks after the last injection. (A) The levels of EPAC1 and EPAC2 proteins were assessed by western blot. Actin was used as a loading control. (B) Body weight of mice at different weeks after treatment with Sal or Dox. Ejection fraction (C) and Left ventricle end-diastolic volume (D) were determined by echocardiography and are presented in bar graphs as mean \pm S.E.M. Calcium transients (E to $\mathbf{G}$ ) and Sarcoplasmic Reticulum load (H-I) were characterized by confocal microscopy. $* \mathrm{P}<0.05,{ }^{* * *} \mathrm{P}<0.001$ vs. WT Saline, $\# \mathrm{P}<0.05$, \#\#P<0.01 vs. EPAC1 KO Saline. (J) The level of SERCA2A protein was measured by western blot. Actin was used as a loading control. Relative protein levels are presented as mean \pm S.E.M. ${ }^{* * *} \mathrm{P}<0.001$ vs. WT Saline. The number of saline or Dox-treated mice are indicated in the bars of the graphs. 


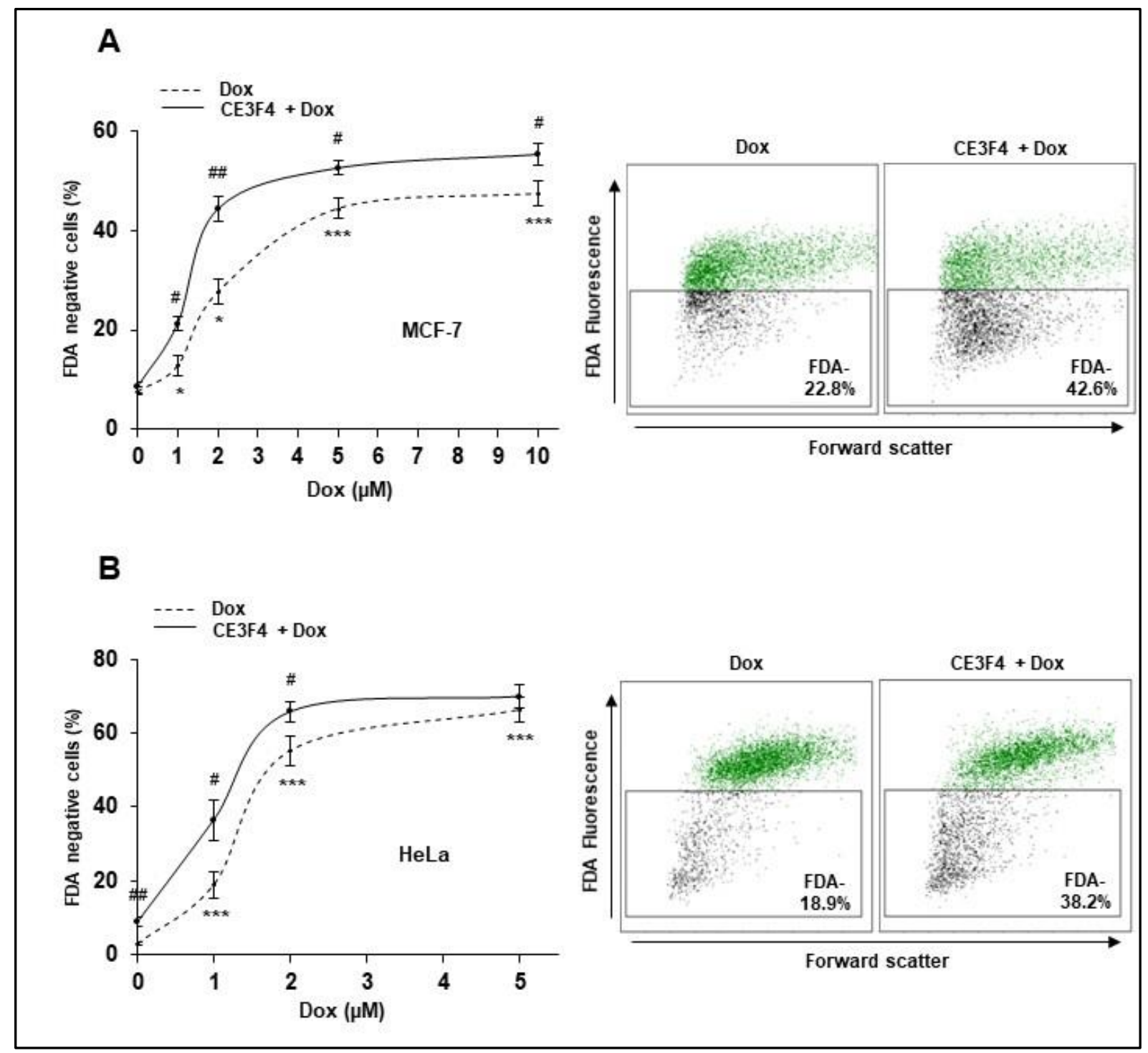

Figure 7. EPAC1 inhibition enhanced Dox-induced cytotoxicity in various human cancer cells

Human MCF-7 breast cancer cells (A), and HeLa cervical cancer cells (B) were left untreated or treated with the indicated doses of Dox +/- CE3F4 $(10 \mu \mathrm{M})$ for $24 \mathrm{~h}$. Cell death was measured by flow cytometry after FDA staining. Results presented in graphs are expressed as the percentage of dead cells (FDA negative cells) (means \pm S.E.M., $\mathrm{n}=5, * \mathrm{P}<0.05, * * * \mathrm{P}<0.001$ vs. control, $\# \mathrm{P}<0.05$, \#\#P<0.01 vs. Dox alone). Representative biparametric cytograms showing forward scatter (cell size) vs. FDA fluorescence are presented. 